\title{
A NEW FORM OF APPARATUS FOR FINDING THE VELOCITY OF SOUND IN THE AIR.
}

Bx A. Haven Smith, Sioux City, Iowa.

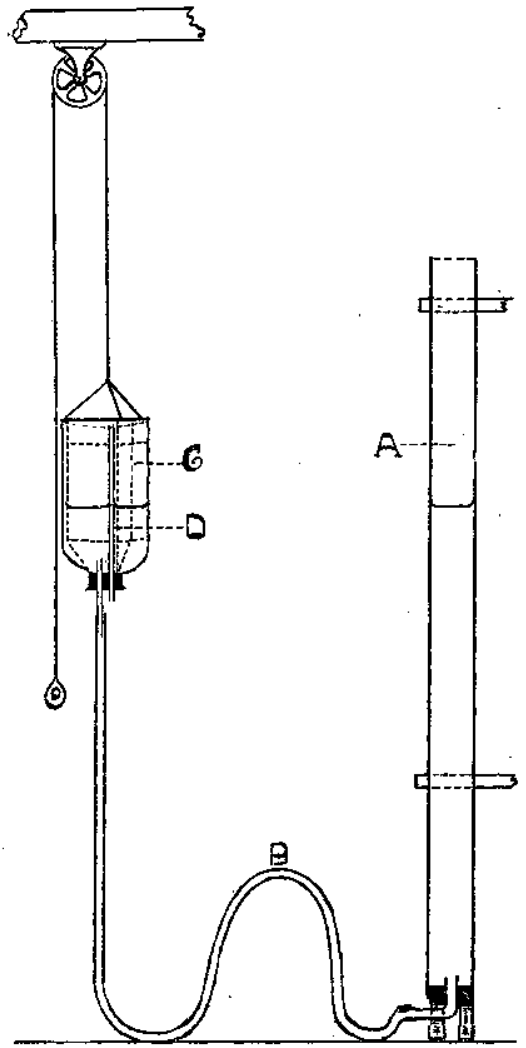

A satisfactory form of apparatus for finding the velocity of sound in air does away with the spilling of water and enables the pupil to work rapidly and accurately.

The tube A, which is about one and one-half meters in length and four centimeters in diameter, is fastened securely to the wall. A corner of the room is the most convenient place to set up the apparatus. In the bottom of the tube is a one-hole rubber stopper through which passes a glass tube about five millimeters in diameter. This is connected with the rubber tubing $\mathrm{B}$ which in turn joins one opening of the bottle $\mathrm{C}$. The tube $\mathrm{D}$ forms an opening for the entrance or escape of the air thus making it possible to use one of the many empty bottles to be found in every laboratory. A cord is fastened to the bottle and made to run over a fixed pulley. Sufficient water to partially fill the tube is poured into the tube and as the bottle is raised or lowered the length of the air column is changed accordingly. By the use of a proper amount it is impossible for the pupil to spill any of the water. With a trube $150 \mathrm{~cm}$ in length, the pupil may be required to find two or even three places of reinforcement and thus secure results of greater accuracy. 